УДК 811.824

ББК 81'

DOI: https://doi.org/10.17308/lic.2020.2/2828

\title{
САЛИШСКИЕ ЯЗЫКИ И ДОИСТОРИЧЕСКИЕ МИГРАЦИИ: ОПЫТ МЕЖДИСЦИПЛИНАРНОГО ИЗУЧЕНИЯ
}

\author{
О. Н. Иконникова \\ Ростовский институт повышения квалификации \\ и профессиональной переподготовки работников образования
}

Д. А. Рубан

Московский государственный университет технологий и управления имени К. Г. Разумовского

\section{THE SALISHAN LANGUAGES AND PREHISTORIC MIGRATIONS: EXPERIMENT OF INTERDISCIPLINARY RESEARCH}

\author{
O. N. Ikonnikova \\ Rostov Institute of Improving Teachers' Qualification and Professional Retraining \\ D. A. Ruban \\ K. G. Razumovsky Moscow State University of Technologies and Management
}

\begin{abstract}
Аннотация: междисииплинарность рассматривается авторами как необходимая методология исследования комплексных проблем, неразрешимых в рамках одной дисциплины. Междисциплинарные исследования, в которых лингвистика является ведущей областью научного знания, способнь пролить свет на проблему заселения Северной Америки в коние плейстоценовой эпохи. По мнению авторов, архаичные индейские салишские языки, локализованные на северо-западе США и юго-западе Канады и обладающие ичивилизационной матрицей, базирующейся на мифологическом сознании, актуальны в исследованиях, связанных с реконструкцией диахронных моделей и исторических прочессов в общеязыковом и междисииплинарном контекстах. Территория распространения салишских языков лежит непосредственно на пути миграции человека в Новый Свет. В настоящзей работе представлено исследование салишских языков с позиций решения проблемы заселения Северной Америки, соответствующий материал анализируется с позиций лингвистики, геомифологии и геохронологии. В результате исследования материалов реконструкиий праформ обнаруживается фонетическое сходство и фонетические соответствия при сравнении базовых лексем основного списка (песок, рыба, давать, рука, сльшать (слушать), глаз, вода, живот, кто, нога (ступня), земля, знать, кровь, этот (тот), гореть, голова) прасалишского языка с прабанту, праенисейским, с семьями ностратического праязыка, а также праалгского, протоалгонкиновакашского, протонивхского языков. Кроме того, авторы выявили закономерность, что ядерные мифологемы (птииа-громовержеи, трикстер и др.) салищей Северо-запада Америки и ряда других регионов мира во многом тождественны, а их возникновение может объясняться контактами человека с представителями мегафауны ледниковой эпохи. Все это указывает на то, что заселение Северной Америки и формирование салишских языков согласуется с общей схемой распространения современного человека из Африки по всему миру, начавшегося порядка 60 тыс. лет назад. Данное исследование указывает на отсутствие аргументов в пользу более раннего или более позднего заселения континента, которое следует датировать кониом плейстоиена, т. е. 15-10 тыс. лет назад.

Ключевые слова: салишские языки, междисииплинарное исследование, мифологемы, заселение Северной Америки, праформы.
\end{abstract}

(С) Иконникова О. Н., Рубан Д. А., 2020

Контент доступен под лицензией Creative Commons Attribution 4.0 License.

The content is available under Creative Commons Attribution 4.0 License. 
Abstract: the authors consider interdisciplinarity as a necessary methodology for studying complex problems that cannot be solved within the framework of one discipline. Interdisciplinary research, linguistics being the leading branch of science, can throw light on the problem of the colonization of North America at the end of the Pleistocene era. According to the authors'view, archaic Indian Salishan languages, localized in the northwest of the USA and southwest of Canada, possessing a civilization matrix based on mythological consciousness, are relevant in research related to the reconstruction of diachronic models and historical processes of the language and in interdisciplinary studies. The territory of distribution of the Salishan languages lies directly on the path of human migration to the New World. This paper represents a study of the Salishan languages in context of solving the problem of the colonization of North America. The relevant material is analyzed in light of synthesis of linguistics, geomythology and geochronology. As a result of the study of the materials of the reconstructed protoforms, phonetic resemblances and phonetic correspondences were found while comparing basic lexemes (sand, fish, give, hand, hear (listen), eye, water, stomach, who, leg (foot), earth, know, blood, this (that), burn, head) of the Swadesh list of the Proto-Salish language with the Proto-Bantu, Proto-Yeniseian, with the families of the Nostratic Proto-language, as well as with the Proto-Algic, Proto-Algonquian-Wakashan, Proto-Nivkh languages. In addition, the authors elicited that the core mythologemes (Thunderbird, Trickster, etc.) of the Salish and several other regions of the world are identical, and their origin could be explained by human contacts with representatives of the megafauna of the Ice Age. The above mentioned indicates that the colonization of North America and the origin of the Salishan languages is consistent with the general pattern of the distribution of the modern humans from Africa around the world, which began about 60 thousand years ago. The research indicates the absence of arguments in favor of earlier or later colonization of the continent, which should be dated to the end of the Pleistocene, i.e. 15-10 thousand years ago.

Key words: Salish languages, interdisciplinary research, mythologems, colonization of North America, protoforms.

Салишские языки - малоизученные, вымирающие, бесписьменные индейские языки северо-запада Америки. Они сохранили в своей системе древние языковые черты, которые позволяют реконструировать диахронные модели и исторические процессы в общеязыковом и междисциплинарном контексте. Определение времени и возможных путей проникновения человека в Северную Америку продолжает составлять существенную проблему, несмотря на длительность изучения с использованием самых различных, в том числе новейших генетических методов [1-3]. Эта проблема носит отчетливо выраженный междисциплинарный характер [4-7], а ее решение предполагает синтез знаний из таких наук и научных дисциплин, как история, археология, этнография, антропология, генетика, краниология, геология, палеонтология и, безусловно, лингвистика. Кроме того, важный материал может дать такое междисциплинарное направление исследований, как геомифология, развивающаяся на стыке геологии, лингвистики и этнографии.

При решении вышеобозначенной проблемы видится исключительно важным максимально конкретизировать объект изучения, сосредоточившись при этом на материале с оптимальной географической привязкой и рассматривая его в широком плане (например, в контексте мирового расселения современного человека). По мнению авторов, салишские языки, локализованные в северо-западной части США и юго-западной части Канады, представляют собой особый интерес для изучения. Территория их распространения и уровень развития вполне позволяют сопоставлять их в культурном отношении (по крайней мере, в плане некоторых наследуемых в течение длительного времени культурных особенностей) с первыми поселенцами Североамериканского континента. Так, Ю. Е. Березкин считает салишей очень древними обитателями своего прибрежного ареала и даже, возможно, прямыми потомками первой волны заселения Америки ввиду большого разнообразия мифологических мотивов, которые сконцентрированы в ареале распространения салишских языков [4]. Немногочисленные современные носители салишских языков веруют в то, что они живут в данном ареале с очень древних времен 'since the beginning of time' [8], 'immemorial time' [9]. Кроме того, салишская группа индейских языков репрезентирует мифологическое сознание, данные языки можно отнести по своему развитию к периоду позднего палеолита [10].

Сказанное выше обусловливает актуальность исследования салишских языков в контексте, связанном с решением проблемы заселения Америки. Целью настоящей работы является рассмотрение салишских языков в междисциплинарном контексте и поиск особенностей, позволяющих обсуждать эту проблему.

Прежде всего необходимо кратко суммировать современные представления о заселении Северной Америки. Согласно общепринятой точке зрения [1, 11-14], таковое происходило в конце плейстоценовой эпохи (порядка 15 тыс. лет назад) через своего рода «мост», связывавший Евразию и Северную Америку на месте современного Берингова пролива (Берингия). Уже 10-11 тыс. лет назад человек широко распространился в Северной Америке (культура Кловис) [4]. 
Глобальное потепление и связанные с ним таяние ледника и подъем глобального уровня моря привели к исчезновению Берингии. Современные салишские племена населяют территорию, которая лежит непосредственно на пути миграции древнего человека вдоль западного побережья Северной Америки. Результаты некоторых новейших исследований позволяют уточнить приведенную выше точку зрения. Так, данные из Южной Америки (Монте-Верде в Чили) свидетельствуют о том, что заселение Америки могло иметь место намного раньше - порядка 20 тыс. лет назад, т. е. до развития культуры Кловис $[15 ; 16]$. Это вполне согласуется с реконструкциями, показывающими возникновение оптимальных условий для миграции через Берингию уже 17-20 тыс. лет назад [17]. Более того, достаточно хорошо обоснован тезис о том, что сама Берингия могла быть заселена уже 30 тыс. лет назад, а североамериканские индейцы произошли от соответствующей популяции [18]. Заселение могло происходить не только по суше, но и вдоль берега с использованием плавсредств, благодаря сосредоточению здесь важных питательных ресурсов [2]. Генетические и антропологические исследования показывают, что миграция человека в Северную Америку могла происходить в одну [3] или две волны [19].

К. Тернер исследовал индейцев и эскимосов и пришел к выводу, что все аборигенное население Нового Света может быть разделено на 3 большие группы: 1) эскимосы-алеуты; 2) индейцы северо-запада Северной Америки; 3) остальные аборигенные популяции Северной и Южной Америк [20]. Эти группы, согласно указанному автору, отражают историю заселения тремя волнами мигрантов: первая - более 15 тыс. лет назад, вторая - между 14 и 12 тысячелетиями до наших дней, третья - примерно 8500 лет назад [20].

Особый интерес в контексте настоящей работы представляют ранее выполненные лингвистические исследования, результаты которых весьма неоднозначны. В своей предшествующей работе, основанной на геомифологическом анализе салишских языков и культуры, авторы показали, что таковые восходят ко времени заселения Северной Америки и могут быть датированы 10-15 тыс. лет назад [6]. Это вполне согласуется с археологическими, антропологическими и генетическими свидетельствами данного события. Известный макрокомпаративист С. Л. Николаев выдвигает гипотезу праалгского языка, постулирующую родство алгонкинских, вакашских и салишских языков Северной Америки, а также нивхского языка Восточной Азии [21]. Этот специалист находит соответствия в стословном списке базовой лексики в праалгонкинском, правакашском, прасалишском, пранивхском языке, а также реконструиру- ет праформы единого праалгонкино-вакашского языка, датируемого около 7 тыс. лет назад [21]. Это не противоречит представлениям о заселении Северной Америки в конце плейстоцена.

Напротив, В. В. Шеворошкин выдвигает гипотезу о переселении салишских племен из Кавказа в Азию, а затем в Северную Америку порядка 5 тыс. лет назад [22]. Он основывается при этом на сопоставлении слов кавказских, салишских и вакашских языков, находя фонетические соответствия у 63 слов из основного 100-словного списка, и приходит к выводу о родстве трех названных групп языков и переселении салишских племен из кавказского ареала на американский континент около 5 тыс. лет назад. Однако такого рода миграция видится маловероятной. С одной стороны, Берингия исчезла порядка 10 тыс. лет назад, после чего массовое перемещение народов через Берингов пролив вряд ли было возможным. С другой стороны, имеются однозначные свидетельства всего лишь одной-двух волн заселения Северной Америки, происходивших гораздо раньше [3; 19]. М. Сиколи и Дж. Холтон показали, что енисейские языки могли произойти от языка популяции, населявшей Берингию, т. е. имела место не однонаправленная миграция из Азии в Северную Америку, а достаточно сложное распространение народов и культур, в том числе и в обратном направлении [23], что, на наш взгляд, видится вполне вероятным. Более того, именно такого рода обратные миграции могли иметь следствием усиление сходства языков пространственно разобщенных популяций. Нельзя исключать, что результаты исследований В. В. Шеворошкина могут толковаться и в таком контексте.

Отмеченные данные и их интерпретации свидетельствуют о том, что проблема заселения Северной Америки требует рассмотрения в контексте расселения современного человека в мировом пространстве. Общепризнано, что это расселение происходило из Африки, при этом реализовывалось оно несколькими эпизодами, из которых основной начался примерно 60-70 тыс. лет назад [24-26]. В восточном направлении пути миграции проходили как по прибрежным регионам Южной и Юго-Восточной Азии и Дальнего Востока, так и непосредственно через центральные, континентальные области Евразии. Установлено, что несмотря на очевидные языковые эволюцию и диверсификацию, отдельные элементы современных языков так или иначе могут быть прослежены вплоть до изначальных протоформ [27]. В контексте настоящего исследования проверка данного утверждения является принципиальной.

А. В. Маловичко и В. Г. Козырский, придерживаясь гипотезы моногенеза и африканского происхождения человека, приводят так называемый «список слов древнего охотника или собирателя» - те слова, 
которые существовали в едином праязыке и в настоящее время являются общими для всех языков мира: вода, огонь, глаз, резать, знать, ребенок, рыба, много, рассказывать, два, камень, ловить, большой, живот, падать [28]. Эти специалисты, используя метод сравнения базовой лексики, находят фонетические корреляции при сравнении слов из данного списка в ностратическом языке (по В. М. Илличу-Свитычу), америндском языке (по Дж. Гринбергу) и нигеро-конголезских языках. Согласно гипотезе отмеченных ученых единым праязыком является нигеро-конголезская языковая семья [7; 28].

Синтезируя материалы реконструкций С. Л. Николаева, В. В. Шеворошкина, А. В. Маловичко, В. Г. Козырского, а также прабанту нигеро-конголезской семьи по М. Гасри [29] с праформами салишских языков, реконструированных А. Куйперсом [30], а также с привлечением материалов реконструкций С. А. и Г. С. Старостиных, извлеченных из этимологической базы «Вавилонская башня» [31], мы можем проследить следующее фонетическое сходство и фонетические соответствия в базисной лексике.

Песок: PS *c'ix, *x' $\dot{x}^{w}, \mathrm{~PB} * c E k E$, PA *kus, PAlt *čaj, PD *kesar, PAfrAs *gac, PY *qe?s - 'песок, песчаный берег'.

Pылба: PS *ci 'рыба, еда', РВ *cu, ЕA *kr, PD *čar, PAlt *koru (cp. PAlt *kula 'большая рыба'), PAfrAs *kar, (cp. *kwl 'большая рыба', PIE * $(s) k^{w} a l$ 'большая рыба'); PAlt *kula /lak, PD *kol, PY*cik. *oke.

Давать: PS * ¿iq $^{\prime} / *_{y} q^{\prime}$, PB *yink, PD *ik, PAlt

Рука: PS *-ak / aka, PW *n'ukw, PAlg *netk, PAW *n'olk'v, PB *kono.

Cльишать, слушать: PS *k'al / qan, PWN *qaxw,

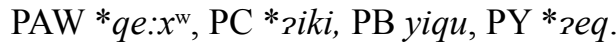

Глаз: PAW *n' - 'видеть, глаз', PW *n'a - 'смотреть', PAlg *new - 'видеть', РА *ank, ЕА * $n j-$ ' 'видеть, глаз' (ср. РІЕ *nеy - 'сверкать, сиять, видеть'), PD *no - видеть, замечать, глаз, PNi *n' $a$ : - 'смотреть, наблюдать', PD *kan - 'глаз, видеть' (ср. ЕА *gwen - 'знать', PIE *genə /gno 'знать').

Вода: PS *- $q^{w} a,-k^{\mathrm{w}} \mathrm{a}-$ 'вода, пить', $\mathrm{PW} * k^{\prime} a$, $2 a k$ 'w, *č 'a - 'пить', РAW *k'we / * $2 e: k^{w}$ - 'вода, пить', PAfrAs *' $q w$, PC *-k’w, PIE *akwa (cp. PIE (Г-И) *ek - ' пить, вода').

Кто (вопросительноеместоимение): PS *ka, PAW $*^{w}$, PB *ka, PAfrAs *kw, *k, PIE * $k^{w} o / k^{w} i$, PC * $k^{w} i$.

Нога, ступня: PW *-cit'a - 'нога, бедро', *-c’i:t - 'ступня', PAlg * cit- $t$ - 'ступня', PAW *ci:t', PY *kirs.

Земля (грунт): $\mathrm{PS} * c{ }^{\prime} i q '$ - 'грязь', $\mathrm{PW}$ *c'akw - 'грязь', PAlg *ačk - 'земля', PAW *č 'akw, РВ *taka - 'земля, грязь, почва', РК * tiqa - 'почва, глина', PY *tวq - 'грязь, глина'. 3нать: PS *tak - 'ощущать', PAfrAs * $2 a k$ - 'знать, видеть', РС *agw, PD *ak - 'видеть', PAfrAs * $2 a k-$ 'знать, видеть', РА * $2 a k$ - 'видеть, знать'.

Кровь: PS *cay, PW *c'i: $x, \mathrm{PAW} * c^{\prime} u: x, \mathrm{EA} *_{2 s x}$ (cp. PIE *esHş).

Эmom, mom: $\mathrm{PW} * d a$, PAlg *t, $\mathrm{PAW} * d, \mathrm{~PB} * d a$, $\mathrm{PNi} * t u, \mathrm{PIE} * t o$, PAlt *ta, PK *ta / ti, PD *tan, PC *d, PAfrAs *t, PY *tu.

Гореть: PS *wal, PWN * q $^{w} a t$, PAW * $q^{w} w e: l$, PK ${ }^{*} c w$, PIE * $g^{w} h e r / g^{w} e r \partial$.

Голова: PS *-iqw / qin, PW *t'uq, PAW *t'iqw, EA *qir; PIE *k'ar/*k'eras / *k'râs - 'голова, волосы' (ср. PIE (Г-И) * $k^{h}$ r - голова, рог); РК *qira, РВ * guidi'волосы', РС *qvem - 'затылок, верхушка', РY *karga.

Живот: PAW *wi:3, PA *waz - 'живот, сердце', PAfrAs *wazin

В вышеприведенных примерах мы использовали следующие условные сокращения: PS - Proto Salish - протосалишский, PB - Proto Bantu - протобанту, PAW - Proto Algonquian Wakashan - протоалгонкиновакашский, PAlg - Proto Algic - протоалгский, PAfrAs - Proto Afro Asiatic - протоафроазиатский, PIE - Proto Indo-European - праиндоевропейский, PA - Proto Agaw - протоагавский, PC - Proto Caucasian - пракавказский, PK - Proto Kartvelian - пракартвельский, PY - Proto Yeniseian - праенисейский, PD - Proto Dravidian - прадравидийский, PNi - Proto Nivkh - пранивхский, PAlt - Proto Altaic - праалтайский, EA - евразийский, Г-И - реконструкции Т. В. Гамкрелидзе, Вяч. Вс. Иванова [32].

Следует отметить, что, являясь сторонниками Московской школы макрокомпаративистики, в исследовании мы использовали реконструкции из системы «Глобальные этимологии» Вавилонской башни [31]. Между тем мы не являемся антагонистами метода массового сравнения Д. Гринберга. В данном исследовании не ставилось целью установление системы фонетических соответствий между праязыками. Фонетическое сходство (а в некоторых случаях и фонетические соответствия в реконструкциях) нами исследовалось в контексте проблемы возможных связей салишских языков с макросемьями и, как следствие, в контексте заявленной в названии статьи проблемы.

Мы полагаем, что фонетическое сходство рассматриваемых лексем, а в некоторых случаях и фонетические соответствия (из основного 100-словного списка М. Сводеша и «Списка древнего охотника, собирателя» А. В. Маловичко, В. Г. Козырского), прасалишского с прабанту, праенисейским, с семьями ностратического праязыка, а также праалгского, протоалгонкино-вакашского, протонивхского языков, не может быть случайным. Само наличие фонетического сходства вполне резонно рассматривать в качестве 
свидетельства очень длинной, но более-менее непрерывной волны миграции, которая началась еще в Африке, а завершилась, в частности, возникновением популяции, на основе которой сформировались в том числе и салишские племена. В этом случае заселение Северной Америки выглядит вполне логичным следствием мирового расселения современного человека в рамках общепринятых миграционных моделей. Предположим, что в случае проникновения предков салишей каким-либо иным путем (например, через Кавказ) или в более позднее время по отношению к главной волне расселения современного человека, эти фонетическое сходство и соответствия оказались бы менее четко выраженными. Однако в действительности налицо достаточно четкие связи салишских и более древних языков, что является лингвистическим свидетельством заселения Северной Америки в конце плейстоцена.

Несомненно, справедлив тезис Ю. Е. Березкина, который предлагает в рамках междисциплинарных исследований привлечь материалы мифологии, а именно ареальное распределение мифологических мотивов, при этом мотив понимается как любой эпизод или образ или комбинация эпизодов и образов, которые обнаруживаются в разных текстах [4]. Сюжетообразующие мотивы могут иметь значительную древность, а их распространение - свидетельствовать о реальных исторических связях. Сюжетообразующие мотивы включают структурные (т. е. неизменяемые) элементы текстов, благодаря которым относительно сложная фабула не распадается и сохраняет самотождественность на протяжении неопределенно долгого времени в пределах огромных территорий, что открывает новые возможности реконструкций [4].

Изучив «Тематическую классификацию и распределение фольклорно-мифологических мотивов по ареалам» Ю. Е. Березкина на ресурсе «Вавилонская башня» [33], мы вычленили мифологемы, которые являются ядерными для мифов салишских племен и имеющих схожие мифологемы в других ареалах.

В частности, сюжетообразующий мотив о птицегромовержце (существо, вызывающее или воплощающее дождь или грозу) мы находим в салишских мифах и словарях салишских языков. Но данная мифологема прослеживается в мифах племен и народов в ареалах, начиная от бантуязычной Африки через Евразию (Европа и Азия, включая Кавказ, Япония (ареал распространения изолированного айнского языка), Сахалин (ареал распространения изолированного нивхского языка), другие регионы Дальнего Востока (в том числе ареал распространения чукотско-камчатских и эскимосско-алеутских языков) до Северной и Южной Америки и даже в Австралии. Такая распространенность данной мифологемы мо- жет свидетельствовать о ее древности, исторических связях между народами.

Мифологема трикстера в воплощении лиса, шакала или койота широко представлена в мифах салишских племен. Койот является одним из центральных героев салишских мифов. Однако тот же мотив мы наблюдаем в мифах бантуязычной Африки, Европы, Азии, Кавказа, в ареале распространения эскимосско-алеутских языков. Примечательно в этой связи, что в древней индоевропейской традиции для обозначения ‘шакала' и ‘лисы' использовалась основа со значением «волк», что указывает на соотнесенность этих животных с волком в представлении индоевропейцев [32]. В своем исследовании относительно данной мифологемы Ю. Е. Березкин поясняет, что «допустимо поэтому предположить, что в плане реальных исторических связей образы трикстераЛиса и трикстера-Койота представляют собой один и тот же мотив. В пользу этого свидетельствуют и сами североамериканские тексты. Лис в них занимает скромное место и чаще всего либо взаимозаменим с Койотом в одних и тех же сюжетах, либо действует в паре с ним. Что касается Койота-трикстера, то он, в свою очередь, может восходить к евразийской Лисе. В Северной Америке в качестве трикстера в единичных случаях действует Волк, которого в данном контексте также можно соотнести с Койотом... Заслуживает внимания и то обстоятельство, что ряд из них (т. е. мифологем. Выделено нами. - О. И. и Д. Р.) распространены не только в Северной Америке и на Кавказе, но и в Африке южнее Caхары, где находилась прародина современного человека...» [33], что, в свою очередь, дает нам предположить и возможное расселение протосалишей из Африки.

Мифологема «Журавли и пигмеи» также встречается в мифах не только салишских племен, но и народов Индии, Китая, Кавказа, Северной и Южной Америки, Европы, Азии, включая ареал распространения изолированных нивхского и айнского языков, а также эскимосско-алеутских языков. Мифологема «Ворон-трикстер» наличествует как в салишских мифах, так и в мифах Австралии, Азии, Северной Америки, Азии, включая ареал распространения изолированных айнского и нивхского языков, а также эскимосско-алеутских языков.

Значительная ареальная однородность вышеприведенных мифологем и соответственно мифологических мотивов может быть связана с последовательной трансляцией мифологем от предковых форм к современным в ходе мирового расселения современного человека в позднем плейстоцене. Особого внимания заслуживает еще один аспект, а именно присутствие в составе мифологем тех, которые обозначают специфических живых существ и, в частности, громовых птиц. Прообразом последних могли слу- 
жить представители мегафауны, имевшей широкое распространение на всех континентах и входившей в соприкосновение с человеком [34]. Подобное уже предполагалось ранее для Северной Америки [6]. В этой связи возникает любопытный вопрос: не является ли повсеместное контактирование человека и мегафауны причиной повсеместного же формирования сходных мифологем? В случае положительного ответа на него придется отказаться от однородности мифологем как свидетельства непрерывности и направленности процесса расселения. Данные о представителях мегафауны, их внешнем виде, поведении, возможностях использования человеком [34] говорят об их достаточной разнородности. В этой связи при независимом друг от друга возникновении мифологем последние бы не отличались однородностью. Однако это характерно лишь для ряда мифологем, как было установлено ранее при изучении салишских языков [6]. Напротив, мифологема громовых птиц и некоторые другие весьма устойчивы у самых разных народов (см. выше). В этой связи имеет смысл предположить ее возникновение в Африке и далее трансляцию по ходу главной волны миграции современного человека, когда новые представители мегафауны интерпретировались в рамках ранее сформировавшихся мифологических воззрений, что способствовало трансляции и одновременно универсализации последних.

По итогам настоящего исследования можно сделать общий вывод о том, что междисциплинарное изучение салишских языков указывает на заселение Северной Америки как выражение общего процесса распространения современного человека из Африки по всему миру (в том числе через прибрежные и внутренние части Евразии), происходившее в позднем плейстоцене. К такому выводу мы приходим на основе следующих соображений:

- во-первых, на основе анализа базовой лексики протосалишского языка в сопоставлении с протоформами языков банту, енисейских, с семьями ностратического праязыка, а также праалгского, протоалгонкино-вакашского, протонивхского языков;

- во-вторых, на основе ареального распространения ядерных салишских мифологем и мифологических мотивов;

- в-третьих, на основе междисциплинарного анализа современных теорий, связанных с заселением Америки, в том числе лингвистических исследований салишских языков, связанных с реконструкциями праформ макросемей.

Данная работа показывает, что именно междисциплинарный подход к исследованию архаичных салишских языков обеспечивает наиболее полное решение проблемы заселения Северной Америки.

\section{ЛИТЕРАТУРА}

1. Goebel T., Waters M. R., O'Rourke D. H. The Late Pleistocene dispersal of modern humans in the Americas // Science. 2008. Vol. 319. Pp. 1497-1502.

2. Erlandson J. M., Braje T. J. From Asia to the Americas by boat? Paleogeography, paleoecology, and stemmed points of the northwest Pacific // Quaternary International. 2011. Vol. 239. Pp. 28-37.

3. Price $M$. Americas peopled in a single wave, ancient genome reveals // Science. 2018. Vol. 359. P. 14.

4. Березкин Ю. Е. Мифы заселяют Америку : ареальное распределение фольклорных мотивов и ранние миграции в Новый Свет. М. : ОГИ, 2007. 360 с.

5. Васильев С. А., Березкин Ю. С., Козинцев А. Г. Сибирь и первые американцы. СПб. : СПбГУ, 2011. $176 \mathrm{c}$.

6. Иконникова О. Н., Рубан Д. А. Междисциплинарный синтез геомифологии и лингвистики : к вопросу о датировке салишских языков // Вестник Воронеж. гос. ун-та. Сер.: Лингвистика и межкультурная коммуникация. 2018. № 1. С. 131-136.

7. Kozyrski W. H., Malovichko A. V. Archaeolinguistics as a Way to Overcome the Impasse in Comparative Linguistics // Journal of Advances in Linguistics. 2018. Vol. 9. Pp. 1313-1323.

8. Stein J. K. Exploring Coast Salish Prehistory. The Archeology of San Juan Island. Seattle and London : University of Washington Press, 2000. 136 p.

9. Mohs G. Spiritual Sites, Ethnic Significance and Native Spirituality: the Heritage and Heritage Sites of the: Sto:lo Indians of British Columbia. URL: summit.sfu.ca/ system/files/iritems1/5887/b15297524.pdf

10. Иконникова О. Н., Заикин А. А. Отражение мифологического сознания в архаичном языке (на материале сэлишских индейских языков) // Проблемы операционализации и интерпретации междисциплинарного знания в контексте современной прикладной философии. Ростов н/Д. : ЮРИУ РАНХ и ГС, 2016. С. 296311.

11. Васильев С. А. Берингия и проблема первоначального заселения человеком Америки. URL: http://archive.li/Ven1q

12. Уайт Дж. М. Индейцы Северной Америки. Быт. Религия. Культура. М. : Центрполиграф, 2006. 251 с.

13. Mulligan C. J., Szathmary E. J. E. The peopling of the Americas and the origin of the Beringian occupation model // American Journal of Physical Anthropology. 2017. Vol. 162. Pp. 403-408.

14. O'Brien M. J., Buchanan B. Cultural learning and the Clovis colonization of North America // Evolutionary Anthropology. 2017. Vol. 26. Pp. 270-284.

15. Dickinson $W . R$. Geological perspectives on the Monte Verde archeological site in Chile and pre-Clovis coastal migration in the Americas // Quaternary Research. 2011. Vol. 76. Pp. 201-210.

16. Saint Pierre M. Antiquity of mtDNA lineage D1g from the southern cone of South America supports pre- 
Clovis migration // Quaternary International. 2017. Vol. 444. Pp. 19-25.

17. Lesnek A. J. et al. Deglaciation of the Pacific coastal corridor directly preceded the human colonization of the Americas // Science Advances. 2018. Vol. 4. P. eaar5040.

18. Hoffecker J. F. et al. Beringia and the global dispersal of modern humans // Evolutionary Anthropology. 2016. Vol. 25. Pp. 64-78.

19. Hubbe M. et al. Testing evolutionary and dispersion scenarios for the settlement of the New World // PLoS ONE. 2010. № 5. Pp. e11105.

20. Зубов $A$. $A$. Биолого-антропологическая характеристика коренного доевропейского населения Америки. URL: https://www.indiansworld.org/Nonmeso/new world_people1.html\#.W4nh4M4zbDc

21. Nikolaev S. L. Toward the reconstruction of ProtoAlgonquian-Wakashan // Journal of Language Relationship. 2017. Vol. 15. P. 250-278.

22. Shevoroshkin $V$. On The Origin of Salish, Wakashnan, and North Caucasian Languages // International Journal of Modern Anthropology. 2008. Vol. 1. Pp. 85-121.

23. Sicoli M. A., Holton G. Linguistic phylogenies support back-migration from Beringia to Asia // PLoS ONE. 2014. Vol. 9. P. e91722.

24. Bae C. J., Douka K., Petraglia M. D. On the origin of modern humans : asian perspectives // Science. 2017. Vol. 358. P. 1269.

25. Hoffecker J. F., Hoffecker I. T. Technological complexity and the global dispersal of modern humans // Evolutionary Anthropology. 2017. Vol. 26. Pp. 285-299.

26. Reyes-Centeno $H$. Out of Africa and into Asia : fossil and genetic evidence on modern human origins and dispersals // Quaternary International. 2016. Vol. 416. Pp. 249-262.

27. Perreault C., Mathew S. Dating the origin of language using phonemic diversity // PLoS ONE. 2012. Vol. 7. P. e35289.

28. Маловичко А. В., Козырский В. Г. Моногенез языка. Предварительные итоги // Происхождение языка и история человечества. 2008. № 3. С. 26-33.

29. Guthrie's Proto-Bantu forms. URL: http://www. cbold.ish-lyon.cnrs.fr/Docs/Guthrie.html

30. Kuipers A. H. Salish Etymological Dictionary // Occasional Papers in Linguistics. 2002. Vol. 16. Pp. 1-240.

31. Старостин С. А., Старостин Г. С. Этимологическая база данных «Вавилонская башня». URL: http:// starling.rinet.ru/babel.php?lan=ru

32. Гамкрелидзе Т. В., Иванов Вяч. Вс. Индоевропейский язык и индоевропейцы. Реконструкция и историкотипологический анализ праязыка и протокультуры : в 2 ч. Ч. 2. Семантический словарь общеиндоевропейского языка и реконструкиця индоевропейской протокультуры. Тбилиси : Издательство Тбилис. ун-та, 1984. $1330 \mathrm{c}$.

33. Березкин Ю. Е. Тематическая классификация и распределение фольклорно-мифологических мотивов по ареалам. URL: http://starling.rinet.ru/cgi-bin/main. cgi?root=/usr/local/www/data/berezkin

34. Martin P. S. Twilight of the Mammoths : Ice Age Extinctions and the Rewilding of America. Berkeley and Los Angeles : University of California Press, 2005. 269 p.

\section{REFERENCES}

1. Goebel T., Waters M. R., O'Rourke D. H. The Late Pleistocene dispersal of modern humans in the Americas. In Science. 2008. Vol. 319. Pp. 1497-1502.

2. Erlandson J. M., Braje T. J. From Asia to the Americas by boat? Paleogeography, paleoecology, and stemmed points of the northwest Pacific. In Quaternary International. 2011. Vol. 239. Pp. 28-37.

3. Price M. Americas peopled in a single wave, ancient genome reveals. In Science. 2018. Vol. 359. P. 14.

4. Berezkin Y. E. Mify zaselyayut Ameriku: Areal'noe raspredelenie fol 'klorny hotivov i rannie migracii $v$ Novyj Svet [Myths Colonize the Americas: Area distribution of folklore motifs and early migrations into the New World]. Moscow: OGI, 2007.

5. Vasil'ev S. A., Berezkin Y. E., Kozinrsev A. G. Sibir' i pervye amerikancy [Siberia and First Americans]. St. Petersburg: Faculty of Philology of the St. Petersburg State University, 2011.

6. Ikonnikova O. N., Ruban D. A. Mezhdistsiplinarnyj sintez geomifologii i lingvistiki: k voprosu o datirovke salishskikh yazykov [Interdisciplinary synthesis of geomythology and linguistics: on the issue of the age of the Salishan languages]. In Proceedings of Voronezh State University. Series: Linguistics and Intercultural Communication. 2018. No. 1. Pp. 131-136.

7. Kozyrski W. H., Malovichko A. V. Archaeolinguistics as a Way to Overcome the Impasse in Comparative Linguistics. In Journal of Advances in Linguistics. 2018. Vol. 9. Pp. 1313-1323.

8. Stein J. K. Exploring Coast Salish Prehistory. The Archeology of San Juan Island. Seattle and London: University of Washington Press, 2000. 136 p.

9. Mohs G. Spiritual Sites, Ethnic Significance and Native Spirituality: the Heritage and Heritage Sites of the Sto:lo Indians of British Columbia. Available at: summit. sfu.ca/system/files/iritems1/5887/b15297524.pdf

10. Ikonnikova O. N., Zaikin A. A. Otrazhenie mifologicheskogo soznaniya $\mathrm{v}$ arhaichnom yazyke (na materiale selishskih indejskih yazykov) [Reflection of Mythological Consciousness in the Archaic Language (within the Framework of the Salishan Indian Languages)]. In Problemy operacionalizacii i interpretacii mezhdisciplinarnogo znaniya $v$ kontekste sovremennoj prikladnoj filosofii. Rostov-on-Don: YuRIU RANHiGS. 2016. Pp. 296-311.

11. Vasiljev S. A. Beringiya i problema pervonachal' nogo zaseleniya chelovekom Ameriki [Beringia and the problem of the Initial Human Colonization of America]. Available at: http://archive.li/Ven1q

12. White J. M. Indejtsy Severnoj Ameriki. Byt. Religiya. Kul'tura [Indians of North America. Life. Religion. Culture]. Moscow: Centrpoligraf, 2006. 251 p. 
13. Mulligan C. J., Szathmary E. J. E. The peopling of the Americas and the origin of the Beringian occupation model. In American Journal of Physical Anthropology. 2017. Vol. 162. Pp. 403-408.

14. O’Brien M. J., Buchanan B. Cultural learning and the Clovis colonization of North America. In Evolutionary Anthropology. 2017. Vol. 26. Pp. 270-284.

15. Dickinson W. R. Geological perspectives on the Monte Verde archeological site in Chile and pre-Clovis coastal migration in the Americas. In Quaternary Research. 2011. Vol. 76. Pp. 201-210.

16. Saint Pierre M. Antiquity of mtDNA lineage D1g from the southern cone of South America supports pre-Clovis migration. In Quaternary International. 2017. Vol. 444. Pp. 19-25.

17. Lesnek A. J., Briner J. P., Lindqvist C., Baichtal J. F., Heaton T. H. Deglaciation of the Pacific coastal corridor directly preceded the human colonization of the Americas. In Science Advances. 2018. Vol. 4. P. eaar5040.

18. Hoffecker J. F., Elias S. A., O'Rourke D. H., Scott G. R., Bigelow N. H. Beringia and the global dispersal of modern humans. In Evolutionary Anthropology. 2016. Vol. 25. Pp. 64-78.

19. Hubbe M., Neves W. A., Harvati K. Testing evolutionary and dispersion scenarios for the settlement of the New World. In PLoS ONE. 2010. Vol. 5. P. e11105.

20. Zubov A. A. Biologo-antropologicheskaya harakteristika korennogo doevropejskogo naseleniya Ameriki [Biological and anthropological characteristics of the indigenous pre-European population of America]. Available at: https://www.indiansworld.org/Nonmeso/new_world_people1.html\#.W4nh4M4zbDc

21. Nikolaev S. L. Toward the reconstruction of ProtoAlgonquian-Wakashan. In Journal of Language Relationship. 2017. Vol. 15. Pp. 250-278.

22. Shevoroshkin V. On The Origin of Salish, Wakashnan, and North Caucasian Languages. In International Journal of Modern Anthropology. 2008. Vol. 1. Pp. 85121.

Ростовский институт повышения квалификации и профессиональной переподготовки работников образования

Иконникова О. Н., кандидат филологических наук, доиент кафедры педагогики

E-mail: iconolga@mail.ru

Московский государственный университет технологий и управления имени К. Г. Разумовского

Рубан Д. А., кандидат геолого-минералогических наук, доцент, научный сотрудник, Philosophiae Doctor (Университет Претории, ЮАР)

E-mail: ruban-d@mail.ru

Поступила в редакциию 12 февраля 2020 г.

Принята к публикаичи 25 марта 2020 г.
23. Sicoli M. A., Holton G. Linguistic phylogenies support back-migration from Beringia to Asia. In PLoS ONE. 2014. Vol. 9. P. e91722.

24. Bae C J., Douka K., Petraglia M. D. On the origin of modern humans: Asian perspectives. In Science. 2017. Vol. 358. P. 1269.

25. Hoffecker J. F., Hoffecker I. T. Technological complexity and the global dispersal of modern humans. In Evolutionary Anthropology. 2017. Vol. 26. Pp. 285-299.

26. Reyes-Centeno H. Out of Africa and into Asia: Fossil and genetic evidence on modern human origins and dispersals. In: Quaternary International. 2016. Vol. 416. Pp. 249-262.

27. Perreault C., Mathew S. Dating the origin of language using phonemic diversity In PLoS ONE. 2012. No. 7. Pp. e35289.

28. Kozyrski W. H., Malovichko A. V. Language monogenesis: preliminary results. In Origin of language and culture: ancient history of mankind. 2008. Vol. 3. Pp. 26-33.

29. Guthrie's Proto-Bantu forms. Available at: http:// www.cbold.ish-lyon.cnrs.fr/Docs/Guthrie.html.

30. Kuipers A. H. Salish Etymological Dictionary. In Occasional Papers in Linguistics. 2002. Vol. 16. Pp. 1-240.

31. Starostin S. A., Starostin G. S. An Etymological Database Project 'The Tower of Babel'. Available at: http:// starling.rinet.ru/babel.php?lan=ru

32. Gamkrelidze T. V., Ivanov Vyach. Vs. Indoevropejskij yazyk i indoevropejtsy. Rekonstruktsiya i istoriko-tipologicheskij analiz prayazyka i protokul tury. V 2-kh ch. CH. 2. Semanticheskij slovar' obshheindoevropejskogo yazyka i rekonstrukitsya indoevropejskoj protokul'tury. Tbilisi: Izdatel'stvo Tbilisskogo universiteta, 1984. $1330 \mathrm{p}$.

33. Berezkin Y. E. Tematicheskaya klassifikaciya $i$ raspredelenie fol'klorno-mifologicheskih motivov po arealam (Analytical Catalogue of Mythological Motifs). Available at: http://starling.rinet.ru/cgi-bin/main.cgi?root=/usr/ local/www/data/berezkin

34. Martin P. S. Twilight of the Mammoths: Ice Age Extinctions and the Rewilding of America. Berkeley and Los Angeles: University of California Press, 2005. 269 p.

Rostov Institute of Improving Teachers' Qualification and Professional Retraining

Ikonnikova O. N., Candidate of Philological Sciences, Associate Professor of the Pedagogical Department

E-mail: iconolga@mail.ru

K. G. Razumovsky Moscow State University of Technologies and Management

Ruban D. A., Candidate of Geological-mineralogical Sciences, Associate Professor, Researcher, Philosophiae Doctor (University of Pretoria, South Africa)

E-mail: ruban-d@mail.ru

Received: 12 February 2020

Accepted: 25 March 2020 


\section{Для цитирования:}

Иконникова О. Н., Рубан Д. А. Салишские языки и доисторические миграции: опыт междисциплинарного изучения // Вестник Воронежского государственного университета. Серия: Лингвистика и межкультурная коммуникация. 2020. № 2. C. 12-20. DOI: https://doi. org/10.17308/lic.2020.2/2828

\section{For citation:}

Ikonnikova O. N., Ruban D. A. The Salishan languages and prehistoric migrations: experiment of interdisciplinapy research. Proceedings of Voronezh State University. Series: Linguistics and Intercultural Communication. 2020. No. 2. Pp. 12-20. DOI: https://doi.org/10.17308/lic.2020.2/2828 